\title{
INCLUSÃO DE PESSOAS COM DEFICIÊNCIA (PCD) NA EDUCAÇÃO SUPERIOR: UM OLHAR A PARTIR DAS POLÍTICAS DE INCLUSÃO
}

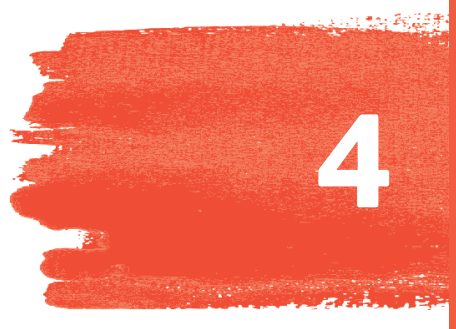

SIMONE VAN DER HALEN FREITAS 10

PAULO FOSSATTI 11

GILCA MARIA LUCENA KORTMANN 12

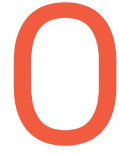

presente texto visa percorrer as políticas de inclusão de pessoas com deficiência na educação superior, no período compreendido entre a promulgação da Constituição Federal de 1988 e a publicação da Lei Brasileira de Inclusão (n. 13.146), de 2015, analisando a evolução nos processos de acesso e permanência. As leis e demais medidas têm como ponto primordial trazer à tona a discussão, mexer com os "tabus" da sociedade.

Ao longo das últimas décadas do século vinte até o momento, os dados oficiais, como o senso do Instituto Brasileiro de Geografia e Estatística (IBGE) e levantamentos do Instituto Nacional de Ensino e Pesquisa (INEP) apontam para inserção de pessoas com deficiência, no ensino superior, devido a medidas e políticas de inclusão

10 Doutoranda do Programa de Pós-Graduação em Educação, docente e coordenadora do Curso de Psicologia da Universidade La Salle/RS, Brasil. E-mail: simone.freitas@unilasalle.edu.br

11 Doutor em Educação. Docente do Programa de Pós-Graduação em Educação e Reitor da Universidade La Salle/RS, Brasil. Líder do Grupo de Pesquisa Ǵestão Educacional em Diferentes Contextos. E-mail: paulo.fossatti@unilasalle.edu.br

12 Doutora em Educação. Docente dos Programas de Pós-Graduação em Saúde e Desenvolvimento Humano e Memória Social e Bens Culturais Universidade La Salle/RS. E-mail: gilca.Iucena@unilasalle.edu.br 
para pessoas com deficiência, buscando cumprir e validar o direito à educação para todos em todos os níveis, princípio fundamental da Constituição brasileira.

No entanto, o fato de ser um princípio previsto em lei não garante o acesso e, principalmente, a permanência das pessoas com deficiência no ensino. O processo de inclusão pressupõe uma mudança cultural na sociedade como um todo. Não é possível pensar a educação de forma isolada. Trata-se de uma caminhada coletiva, na qual estudos e pesquisas desmistificam antigos entendimentos discriminatórios e revelam os potenciais e as possibilidades das pessoas com deficiência. Há muitas barreiras a serem superadas para alcançar a inclusão plena.

Este texto se propõe a uma reflexão; visa estimular a discussão sobre o tema e apontar o que já existe e o quanto cresceu o ingresso de pessoas com deficiência no ensino superior a partir de políticas de inclusão. Inicialmente, apresenta-se um breve resgate dos conceitos e nomenclaturas em relação aos termos inclusão e pessoa com deficiência, permitindo o entendimento do contexto e percepções da sociedade atual em relação às pessoas com deficiência. Adiante, resgatam-se as políticas de inclusão em um recorte, desde a Constituição Federal de 1988, e os apontamentos específicos em relação à educação superior. Para finalizar, propõe-se uma análise da trajetória das pessoas com deficiência, do acesso à permanência no ensino superior.

\section{CONCEITUANDO E CONTEXTUALIZANDO A TRAJETÓRIA DAS PESSOAS COM DEFICIÊNCIA}

Ao se referir à inclusão de Pessoas com Deficiência (PCD) na educação superior, cabe uma contextualização e uma delimitação preliminar dos termos inclusão, pessoa com deficiência e educação superior, como forma de esclarecimento e compreensão da temática. 
Segundo Sassaki (2006), inclusão é o processo de tornar adequados os sistemas sociais comuns para toda a diversidade humana e contar com as próprias pessoas para a execução das adequações. Propor a inclusão é muito mais que se pensar no acesso à educação, ou mercado de trabalho, é consolidar um paradigma de sociedade inclusiva, composta por etnia, raça, língua, nacionalidade, gênero, orientação sexual, deficiência e outros atributos.

O mesmo ocorre ao se definir a expressão pessoas com deficiência (PCD), que já transitou também por termos como Pessoas Portadoras de Deficiência (PPD) e Pessoas com Necessidades Especiais (PNE). Tanto a nomenclatura Portadores como a que se refere a Necessidades Especiais são restritivas e excludentes. Portanto, faz-se necessário um entendimento a cerca desta terminologia, a fim de uma melhor compreensão sobre a evolução, entendimento e valores da sociedade a cada época. O intuito é adotar a terminologia mais compatível e coerente com a premissa de uma sociedade inclusiva.

Para Sassaki (2003) não há um único termo correto e válido, permanentemente, para todas as culturas e épocas. Os termos adotados, a cada período, dizem dos valores vigentes para a sociedade, seu relacionamento e entendimento sobre as pessoas com alguma deficiência. Observando o contexto brasileiro, o mesmo autor aponta, a partir do século 20, chegando aos dias de hoje, oito épocas distintas até os conceitos e terminologias adotados atualmente. Até a década de 60, a nomenclatura usual era "incapacitados", referindose a qualquer tipo de deficiência e sugerindo que tais pessoas eram incapazes, visto que, qualquer que fosse a deficiência, afetariam os aspectos psicológicos, sociais, físicos e profissionais. Entre os anos 60 e 80, passou-se a utilizar três termos, como forma de diferenciar os tipos de deficiências. "Defeituosos" era a denominação para os 
indivíduos com "deformidades" físicas. "Deficientes" se empregava para designar as pessoas com deficiência física, mental, auditiva, visual e múltiplas, as quais levam a executar as tarefas da vida de forma diferente. E o terceiro termo, "os excepcionais", focando pessoas com deficiência mental. Em paralelo, é nessa mesma época que se inicia um movimento pelos direitos das pessoas superdotadas (expressão, posteriormente substituída por pessoas com altas habilidades), visto que também são tidas como excepcionais.

Na década de 80, o ano de 1981 é escolhido como o "Ano Internacional das Pessoas Deficientes”, pela ONU (Organização das Nações Unidas), gerando maior mobilização pelo movimento de busca de direitos sociais. A partir deste ano, substitui-se o termo indivíduo por pessoa como o substantivo que acompanha o adjetivo deficiente, buscando-se igualar os direitos e tratamento com dignidade concedidos a todas as pessoas. Essa década marca um período de maior visibilidade e esclarecimentos à sociedade, em relação às pessoas deficientes. A OMS (Organização Mundial da Saúde) lança a classificação mundial de impedimentos, deficiências e incapacidades, demonstrando o que, de cada uma dessas categorias, encontra-se presente nas pessoas com deficiência (Sassaki, 2003).

No período entre 1988 e 1993, Sassaki (2003) resgata que houve mais um passo em prol da humanização e entendimento das Pessoas com Deficiência, quando líderes de organizações contestam o termo "Pessoas Deficientes", sinalizando uma pessoa inteira como deficiente, dando margem a preconceitos e exclusão. Diante disto, nos países de língua portuguesa, passa-se a adotar o termo Pessoa Portadora de Deficiência, designando que a deficiência pode ser um detalhe, apenas, da pessoa. Este termo, torna-se a nomenclatura oficial, constando nos documentos oficiais, como a constituição federal, políticas, conselhos e coordenadorias. 
Em paralelo ao novo termo, Pessoas Portadoras de Deficiência (PPD), adotado oficialmente na década de 1990, Sassaki (2003) aponta para o surgimento do termo "Necessidades Especiais", em substituição à palavra "Deficiência", propondo-se a nomenclatura "Pessoas Portadoras de Necessidades Especiais". Mas, a partir de uma Resolução do Conselho Nacional de Ensino (CNE), o termo passa a ter significado próprio e passa a ser agregado tanto a pessoas com deficiência quanto a outras pessoas. O termo pessoas especiais vem como uma forma reduzida e passa a designar diversos grupos, como alunos especiais, pacientes especiais, entre outros. O adjetivo "especial" designa um eufemismo, como forma de amenizar a contundência da palavra "deficiente", retratando, novamente, uma invisibilidade da população com deficiência.

Somente em junho de 1994, a partir da Declaração de Salamanca, que preconizava a educação inclusiva para todos, tendo ou não deficiência, deriva-se a expressão "Pessoas com Deficiência e Pessoas sem Deficiência", compreendida como um empoderamento para a população com deficiência, visto que explicita o segmento dos excluídos e exige a inclusão em todos os aspectos da vida e da sociedade. Desde então, o termo Pessoas com Deficiência (PCD) passa a ser adotado pelas próprias pessoas com deficiência, as quais entendem que não são "portadoras" (Sassaki, 2003).

O quadro 1, a seguir, apresenta a síntese das nomenclaturas e termos que designaram as Pessoas com Deficiência, desde o século 20 aos dias de hoje, retratando uma trajetória em busca do reconhecimento e de igualdade de direitos que perpassam os significados das expressões. 
Quadro 1 - Síntese das nomenclaturas adotadas para designar pessoas com deficiência.

\begin{tabular}{|c|c|c|}
\hline Período & Nomenclatura & Contexto \\
\hline $\begin{array}{l}\text { Década } \\
\text { de } 1960\end{array}$ & Incapacitados & $\begin{array}{l}\text { Compreensão de que qualquer deficiência eliminaria } \\
\text { ou reduziria a capacidade das pessoas nos aspectos } \\
\text { físico, psicológico, social e profissional. }\end{array}$ \\
\hline $\begin{array}{l}\text { Entre os } \\
\text { anos } 60 \\
\text { e } 80\end{array}$ & $\begin{array}{l}\text { Defeituosos, } \\
\text { Deficientes e } \\
\text { Excepcionais }\end{array}$ & $\begin{array}{l}\text { Maior mobilização pela busca dos direitos sociais. } \\
\text { Maior visibilidade e esclarecimento da sociedade em } \\
\text { relação às pessoas com deficiência. }\end{array}$ \\
\hline $\begin{array}{l}\text { Década } \\
\text { de } 1980\end{array}$ & $\begin{array}{l}\text { Substituição do termo } \\
\text { indivíduo por pessoa: } \\
\text { "Pessoa Deficiente" }\end{array}$ & $\begin{array}{l}\text { Mobilização das organizações de pessoas deficientes } \\
\text { leva a ONU a declarar } 1981 \text { o Ano Internacional da } \\
\text { Pessoa Deficiente. }\end{array}$ \\
\hline Em 1988 & $\begin{array}{l}\text { Pessoa Portadora de } \\
\text { Deficiência }\end{array}$ & $\begin{array}{l}\text { Constituição Federal de 1988, apontando como um de } \\
\text { seus fundamentos a dignidade da pessoa humana e } \\
\text { o compromisso com a erradicação das desigualdades } \\
\text { sociais e a promoção do bem de todos sem } \\
\text { preconceito ou discriminação (Brasil, 1988). }\end{array}$ \\
\hline $\begin{array}{l}\text { Década } \\
\text { de } 1990\end{array}$ & $\begin{array}{l}\text { Pessoas com } \\
\text { Necessidades Especiais }\end{array}$ & $\begin{array}{l}\text { Declaração Mundial sobre Educação para todos/ } \\
\text { Unesco. }\end{array}$ \\
\hline Em 1994 & Pessoas com Deficiência & $\begin{array}{l}\text { Declaração de Salamanca fomenta o empoderamento } \\
\text { para os movimentos em defesa das pessoas com } \\
\text { deficiência, pressionando para inclusão em todos os } \\
\text { aspectos da vida e na sociedade. }\end{array}$ \\
\hline
\end{tabular}

Fonte: elaboração dos autores, a partir de SASSAKI (2003).

Assim como a nomenclatura que designa as pessoas com deficiência, a inclusão social passa também por diferentes etapas, que denotam o entendimento e o envolvimento da sociedade na trajetória e no movimento para assegurar direitos humanos às Pessoas com Deficiência (PCD).

Carvalho (2010) se refere a quatro fases distintas nesse processo: exclusão, segregação, integração e inclusão. Na fase da exclusão, a PCD fica totalmente isolada do convívio social. Na fase de segregação, passa a ser atendida por instituições específicas, as quais prestam os mais diversos serviços a essa população, mas 
ainda mantendo a PCD separada do convívio social. Na terceira fase, a integração se caracteriza pela inserção desse público (PCD) em espaços comuns, porém sem um serviço especializado de acolhimento ou acompanhamento. $\mathrm{Na}$ fase da verdadeira inclusão, as instituições e espaços públicos promovem as condições necessárias e suficientes para quem tem necessidades especiais diversificadas. Compreende-se que, na última fase, a acessibilidade e a inclusão andam lado a lado.

Todas as diferentes nomenclaturas para designar pessoas com deficiência (PCD), bem como as distintas fases da inclusão social propostas, retratam o entendimento da sociedade e impactam ou traduzem as medidas e movimentos em outros âmbitos, como a educação, recorte proposto por este artigo. A seguir, serão resgatados os marcos legais no Brasil, como leis, decretos e medidas provisórias que contemplam ações para a educação inclusiva, como forma de refletir sobre as possibilidades de acesso e permanência das pessoas com deficiência (PCD) no ensino superior.

\section{A TRAJETÓRIA DO DIREITO À EDUCAÇÃO DAS PESSOAS COM DEFICIÊNCIA}

O direito à educação para todos é um dos princípios básicos preconizados na Constituição Federal de 1988. Partindo daí, desponta-se uma trajetória de medidas provisórias, decretos, leis, resoluções, declarações, políticas e portarias no intuito de assegurar a educação em todos os níveis e ao longo da vida e sem qualquer tipo de discriminação.

Com o foco no público PCD (Pessoas com Deficiência), objetivo desta pesquisa, pode-se partir do entendimento proposto pela Política Nacional de Educação Especial, de 2008, que propõe a pers- 
pectiva de uma educação inclusiva como parte de um movimento mundial pela inclusão. Trata-se de uma ação política, cultural, social e pedagógica em defesa aos direitos humanos. A educação inclusiva se constitui um paradigma fundamentado na concepção que conjuga igualdade e diferença como valores indissociáveis na busca pela superação da exclusão e da segregação na escola.

A partir de uma metodologia de análise documental, percorrem-se diversos marcos legais que norteiam as políticas e práticas de ensino, visando estabelecer uma linha no tempo sobre a inclusão de pessoas com deficiência na educação superior. Luedke e André (1986) apresentam a análise documental como uma técnica pertinente a estudos qualitativos e com foco nas ciências sociais e da educação. Mostra-se uma técnica viável a desvelar aspectos novos a um tema ou problema.

O quadro 2, a seguir, apresenta os dados coletados nos documentos analisados para o propósito deste estudo.

\section{Quadro 2}

\begin{tabular}{|c|c|}
\hline Marcos Legais & Aspectos referentes à inclusão de PCD na educação \\
\hline $\begin{array}{l}\text { Constituição } \\
\text { Federal de } \\
1988\end{array}$ & $\begin{array}{l}\text { Promover o bem a todos, sem preconceitos de origem, raça, sexo, cor, idade e } \\
\text { quaisquer outras formas de discriminação (art. 3, inciso IV); Educação como um } \\
\text { direito para todos (art. 205); Igualdade de condições de acesso e permanência } \\
\text { na escola (art. 206, inciso I); Oferta de atendimento educacional especializado, } \\
\text { preferencialmente, na rede regular de ensino (art. 208). }\end{array}$ \\
\hline Lei 7.853-1989 & $\begin{array}{l}\text { Dispõe sobre a Coordenadoria Nacional para Integração da Pessoa Portadora } \\
\text { de Deficiência (Corde); Prevê a matrícula compulsória em cursos regulares de } \\
\text { estabelecimentos públicos e particulares de pessoas portadoras de deficiência } \\
\text { capazes de se integrarem no sistema regular de ensino; Criminaliza a recusa a } \\
\text { inscrição de aluno em estabelecimento de ensino de qualquer curso ou grau, } \\
\text { público ou privado, por motivos derivados da deficiência que porta. }\end{array}$ \\
\hline $\begin{array}{l}\text { Declaração de } \\
\text { Jomtien } 1990\end{array}$ & $\begin{array}{l}\text { Determina o fim de preconceitos e estereótipos de qualquer natureza na } \\
\text { educação; Brasil assumiu o compromisso de erradicar o analfabetismo } \\
\text { e universalizar o ensino fundamental no país, através da construção de } \\
\text { sistemas educacionais inclusivos. }\end{array}$ \\
\hline
\end{tabular}




\begin{tabular}{|c|c|}
\hline $\begin{array}{l}\text { Política } \\
\text { Nacional de } \\
\text { Educação } \\
\text { Especial (1994) }\end{array}$ & $\begin{array}{l}\text { Orienta o processo de "integração instrucional", que condiciona o acesso às } \\
\text { classes comuns do ensino regular àqueles que "(...) possuem condições de } \\
\text { acompanhar e desenvolver as atividades curriculares programadas do ensino } \\
\text { comum, no mesmo ritmo que os alunos ditos normais" (p. 19). }\end{array}$ \\
\hline Lei 8.859/94 & $\begin{array}{l}\text { Estende aos alunos de ensino especial o direito à participação em atividades } \\
\text { de estágio }\end{array}$ \\
\hline $\begin{array}{l}\text { Declaração } \\
\text { de Salamanca } \\
(1994)\end{array}$ & $\begin{array}{l}\text { Independente das diferenças individuais, a educação é direito de todos; } \\
\text { Toda criança que possui dificuldade de aprendizagem pode ser considerada } \\
\text { com necessidades educativas especiais; A escola deve adaptar-se às } \\
\text { especificidades dos alunos, e não os alunos às especificidades da escola; } \\
0 \text { ensino deve ser diversificado e realizado num espaço comum a todas as } \\
\text { crianças. }\end{array}$ \\
\hline $\begin{array}{l}\text { Portaria MEC } \\
1.793 / 94\end{array}$ & $\begin{array}{l}\text { Recomenda a inclusão da disciplina Aspectos Ético-Político-Educacionais na } \\
\text { normalização e integração da pessoa portadora de necessidades especiais, } \\
\text { prioritariamente, nos cursos de Pedagogia, Psicologia e em todas as } \\
\text { Licenciaturas. }\end{array}$ \\
\hline $\begin{array}{l}\text { Lei 9.394/1996 } \\
\text { (LDB) - Lei } \\
\text { de Diretrizes } \\
\text { e Bases da } \\
\text { Educação }\end{array}$ & $\begin{array}{l}\text { Assegura a terminalidade específica àqueles que não atingiram o nível } \\
\text { exigido para a conclusão do ensino fundamental, em virtude de suas } \\
\text { deficiências; Contém um capítulo para tratar da educação especial (Capítulo } \\
\text { V da LDB), prevendo a oferta de educação "preferencialmente" na rede } \\
\text { regular para os alunos deficientes, a oferta de serviço de apoio especializado } \\
\text { na escola regular para atender às peculiaridades da clientela. }\end{array}$ \\
\hline $\begin{array}{l}\text { Decreto } n \text {. } \\
\text { 3.298/1999 }\end{array}$ & $\begin{array}{l}\text { Dispõe sobre a Política Nacional para a Integração da Pessoa Portadora de } \\
\text { Deficiência. Propõe a matrícula compulsória de pessoas com deficiência, em } \\
\text { cursos regulares, a consideração da educação especial como modalidade } \\
\text { de educação escolar que permeia transversalmente todos os níveis e } \\
\text { modalidades de ensino, a oferta obrigatória e gratuita da educação especial } \\
\text { em estabelecimentos públicos de ensino. }\end{array}$ \\
\hline $\begin{array}{l}\text { Declaração } \\
\text { Internacional } \\
\text { de Montreal } \\
\text { sobre Inclusão } \\
\text { (2001) }\end{array}$ & $\begin{array}{l}\text { Estabelece que o acesso igualitário a todos os espaços da vida é um pré- } \\
\text { requisito para os direitos humanos universais e liberdades fundamentais das } \\
\text { pessoas. }\end{array}$ \\
\hline $\begin{array}{l}\text { Decreto } \\
3.956 / 2001\end{array}$ & $\begin{array}{l}\text { Promulga a Convenção Interamericana da Guatemala para a Eliminação } \\
\text { de Todas as Formas de Discriminação contra as Pessoas Portadoras de } \\
\text { Deficiência. }\end{array}$ \\
\hline $\begin{array}{l}\text { Resolução CNE/ } \\
\text { CEB 02/2001 }\end{array}$ & $\begin{array}{l}\text { Refere que os sistemas de ensino devem matricular todos os alunos, } \\
\text { cabendo às escolas se organizarem para o atendimento aos educandos com } \\
\text { necessidades educacionais especiais, assegurando as condições necessárias } \\
\text { para uma educação de qualidade para todos. }\end{array}$ \\
\hline
\end{tabular}




\begin{tabular}{|c|c|}
\hline $\begin{array}{l}\text { Plano Nacional } \\
\text { de Educação } \\
\text { (PNE), lei n. } \\
10.172 / 2001\end{array}$ & $\begin{array}{l}\text { Propõe a construção de uma escola inclusiva que, garanta o atendimento } \\
\text { à diversidade humana. Entre os objetivos e metas para a educação das } \\
\text { pessoas com necessidades educacionais especiais estabelecidos no } \\
\text { PNE, destacam-se: a) os padrões mínimos de infraestrutura das escolas } \\
\text { para atendimento de alunos com necessidades educacionais especiais; } \\
\text { b) da formação inicial e continuada dos professores para atendimento } \\
\text { às necessidades dos alunos; c) da disponibilização de recursos didáticos } \\
\text { especializados de apoio à aprendizagem nas áreas visual e auditiva; d) da } \\
\text { articulação das ações de educação especial com a política de educação para } \\
\text { o trabalho. }\end{array}$ \\
\hline $\begin{array}{l}\text { Lei } \\
10.436 / 2002\end{array}$ & $\begin{array}{l}\text { Estabelece a Libras (língua brasileira de sinais), como língua oficial no País } \\
\text { juntamente com o Português. }\end{array}$ \\
\hline $\begin{array}{l}\text { Resolução CNE/ } \\
\text { CP 01/2002 }\end{array}$ & $\begin{array}{l}\text { Sobre a formação de professores da educação básica, define que as } \\
\text { instituiç̃ões de ensino superior devem prever, em sua organização curricular, } \\
\text { formação docente voltada para a atenção à diversidade e que contemple } \\
\text { conhecimentos sobre as especificidades dos alunos com necessidade } \\
\text { educacionais especiais. }\end{array}$ \\
\hline $\begin{array}{l}\text { Portaria MEC } \\
2.678 / 2002\end{array}$ & Difusão do Sistema Braille em todas as modalidades de ensino. \\
\hline $\begin{array}{l}\text { Lei } \\
10.845 / 2004\end{array}$ & $\begin{array}{l}\text { Programa de Complementação ao Atendimento Educacional Especializado } \\
\text { às Pessoas Portadoras de Deficiência (PAED), com objetivos principais de } \\
\text { garantir a universalização do atendimento especializado de educandos } \\
\text { portadores de deficiência, cuja situação não permita a integração em classes } \\
\text { comuns de ensino regular e garantir, progressivamente, a inserção dos } \\
\text { educandos portadores de deficiência nas classes comuns de ensino regular. }\end{array}$ \\
\hline $\begin{array}{l}\text { Decreto } \\
5.626 / 2005\end{array}$ & $\begin{array}{l}\text { a formação de docentes para o ensino de Libras nas séries finais do ensino } \\
\text { fundamental, no ensino médio e na educação superior deve ser realizada em } \\
\text { nível superior, em curso de graduação de licenciatura plena em Letras: Libras } \\
\text { ou em Letras: Libras/Língua Portuguesa como segunda língua. }\end{array}$ \\
\hline $\begin{array}{l}\text { Convenção } \\
\text { sobre os } \\
\text { Direitos das } \\
\text { Pessoas com } \\
\text { Deficiência } \\
\text { (CDPD) } 2006\end{array}$ & $\begin{array}{l}\text { Assegurar um sistema de educação inclusiva em todos os níveis de ensino, } \\
\text { em ambientes que maximizem o desenvolvimento acadêmico e social } \\
\text { compatível com a meta da plena participação e inclusão, adotando medidas } \\
\text { para garantir que: a) pessoas com deficiência não sejam excluídas do } \\
\text { sistema educacional; e, b) as pessoas com deficiência possam ter acesso } \\
\text { ao ensino fundamental inclusivo, de qualidade e gratuito, em igualdade de } \\
\text { condições com as demais pessoas na comunidade em que vivem. }\end{array}$ \\
\hline
\end{tabular}




\begin{tabular}{|c|c|}
\hline $\begin{array}{l}\text { Decreto } \\
6.094 / 2007\end{array}$ & $\begin{array}{l}\text { Em 2007, foi lançado o Plano de Desenvolvimento da Educação (PDE), } \\
\text { reafirmado pela Agenda Social, tendo como eixos a formação de } \\
\text { professores para a educação especial, a implantação de salas de recursos } \\
\text { multifuncionais, a acessibilidade arquitetônica dos prédios escolares, o } \\
\text { acesso e a permanência das pessoas com deficiência na educação superior } \\
\text { e o monitoramento do acesso à escola dos favorecidos pelo Benefício de } \\
\text { Prestação Continuada (BPC). }\end{array}$ \\
\hline $\begin{array}{l}\text { Decreto } \\
\text { legislativo } \\
186 / 2008\end{array}$ & Aprova o texto da Convenção sobre os Direitos das Pessoas com Deficiência. \\
\hline $\begin{array}{l}\text { Decreto } \\
6.949 / 2009\end{array}$ & $\begin{array}{l}\text { Promulga a Convenção Internacional sobre os Direitos das Pessoas com } \\
\text { Deficiência. }\end{array}$ \\
\hline $\begin{array}{l}\text { Resolução CNE/ } \\
\text { CEB 04/2009 }\end{array}$ & $\begin{array}{l}\text { Apresenta Diretrizes Operacionais para o Atendimento Educacional } \\
\text { Especializado na Educação Básica, modalidade Educação Especial. AEE - } \\
\text { Atendimento Educacional Especializado como um “serviço" da Educação } \\
\text { Especial assegurado na legislação brasileira através da Constituição de } 1988 .\end{array}$ \\
\hline $\begin{array}{l}\text { Decreto } \\
7.611 / 2011\end{array}$ & $\begin{array}{l}\text { Dispõe sobre a educação especial, o atendimento educacional especializado } \\
\text { e dá outras providências. Institui o Plano Nacional dos Direitos da Pessoa } \\
\text { com Deficiência - Plano Viver sem Limite. }\end{array}$ \\
\hline $\begin{array}{l}\text { Novo Plano } \\
\text { Nacional de } \\
\text { Educação (PNE) } \\
2011-2020\end{array}$ & $\begin{array}{l}\text { Documento que servirá como diretriz para todas as políticas educacionais do } \\
\text { País. META } 4 \text { - Universalizar, para a população de quatro a dezessete anos, } \\
\text { o atendimento escolar aos alunos com deficiência, transtornos globais do } \\
\text { desenvolvimento e altas habilidades ou superdotação, preferencialmente, na } \\
\text { rede regular de ensino, garantindo o atendimento educacional especializado } \\
\text { em classes, escolas ou serviços especializados, públicos ou comunitários, } \\
\text { sempre que, em função das condições específicas dos alunos, não for } \\
\text { possível sua integração nas classes comuns. }\end{array}$ \\
\hline $\begin{array}{l}\text { Lei Brasileira de } \\
\text { Inclusão - lei n. } \\
\text { 13.146, de } 6 \text { de } \\
\text { julho de } 2015\end{array}$ & $\begin{array}{l}\text { Propõem acesso à educação superior e à educação profissional e tecnológica } \\
\text { em igualdade de oportunidades e condições com as demais pessoas. }\end{array}$ \\
\hline $\begin{array}{l}\text { Lei } 13.409 / \\
2016\end{array}$ & $\begin{array}{l}0 \text { texto altera a lei que instituiu as cotas no ensino superior federal (Lei } \\
12.711 / 2012) \text {, passando a contemplar as pessoas com deficiência, além de } \\
\text { negros, pardos e indígenas, bem como alunos de baixa renda oriundos da } \\
\text { escola pública. }\end{array}$ \\
\hline
\end{tabular}

Fonte: elaboração dos autores, baseada em https://cmoreira2.jusbrasil.com.br/artigos/111821610/ marcos-historicos-e-legais-da-educacao-especial-no-brasil 
A retrospectiva apresentada, pelos documentos citados, denota a evolução de entendimento acerca dos conceitos e denominações, assim como acompanha o contexto educacional e social de cada período.

Paulatinamente, verifica-se uma tentativa de compreensão sobre diferença e diversidade e uma busca pela igualdade de direitos a todos. A diferença é o que o outro é; a não identidade, o diverso, que leva à desigualdade (Silva, 2002). Em contextos de exclusão e segregação, conforme descreve Carvalho (2010), a diferença desencadeia o extermínio e a reclusão. A diferença ameaça a ordem social.

Já a diversidade pode ser compreendida como multiplicidade de culturas, inserida em algo maior, em um complexo de significados, crenças e valores (Abramowicz, 2007). A diversidade utilizada para apaziguar a diferença e não como sinônimos. É a que se propõem as etapas de integração e inclusão, propostas por Carvalho (2010): promover o acesso e o convívio das diferenças em espaços comuns.

A partir da aprovação da Constituição de 1988, percebe-se um processo em busca de promoção dos direitos humanos e de um discurso de tratamento de igualdade a todos. No que diz respeito às pessoas com deficiência, há momentos de avanço tanto nos aspectos ligados aos acessos à educação como no caso da lei 7.853-1989, que prevê a matrícula compulsória das pessoas portadoras de deficiência em cursos regulares (Brasil, 1989), promovendo a integração no contexto social.

Documentos internacionais como as Declarações de Jomitien (1990) e de Salamanca (1994) e, mais recentemente, a Declaração Internacional de Montreal sobre Inclusão (2001) remetem a um contexto de inclusão da diversidade e comprometem os países signatários a se responsabilizarem em adotar políticas públicas que promovam a igualdade de oportunidades para todos, em uma trajetória para a educação inclusiva. 
Nesse sentido, a partir da década de 1990, surgem no Brasil diversas políticas, leis, decretos e resoluções que vão ao encontro da integração das pessoas portadoras de deficiência (nomenclatura da época) no contexto educacional e na sociedade como um todo. A Política Nacional da Educação Especial, de 1994, lei 8.859/94, portaria MEC n. 1.793/94, Lei de Diretrizes e Bases (LDB), de 1996, decreto n. 3.298/1999 referem a inserção deste público na escola regular, a possibilidade de estágio para alunos especiais, a inserção de disciplinas que abordem a temática, na preparação de profissionais da educação, garantia da oferta de vagas gratuitas no ensino público.

No entanto, ainda há uma tentativa de transformação das diferenças e não da aceitação e convívio em um enfoque de diversidade. Exemplificando, a Política Nacional da Educação Especial de 1994, aos se referir à integração instrucional de crianças portadoras de deficiência faz a seguinte ressalva: “(...) possuem condições de acompanhar e desenvolver as atividades curriculares programadas do ensino comum, no mesmo ritmo que os alunos ditos normais" (Brasil, 1994 p. 19).

A partir dos anos 2000, os documentos legais propõe uma reflexão e iniciam a mudança de paradigma. Os textos já referem aos termos inclusão e inclusivos, como uma evolução da nomenclatura integração. O Plano Nacional de Educação e a resolução CNE/ CEB 2/2001 propõem ações e demandas de adaptação do contexto, infraestrutura e preparo de pessoas habilitadas para o acolhimento dos alunos com deficiências.

A resolução CNE/CEB 4/2009 institui o Atendimento Educacional Especializado (AEE) como um "serviço" a ser ofertado pelas instituições de ensino para assegurar o atendimento às necessidades específicas na promoção da inclusão das pessoas com deficiência. Esses são os primeiros passos para a implantação de um con- 
texto inclusivo, em que o ambiente se prepara para compreender e atender as diferenças. Atendendo a tendência voltada à inclusão, a Lei Brasileira de Inclusão, de 2015, registra a mudança da nomenclatura de "Pessoa Portadora de Deficiência" para "Pessoa com Deficiência", procurando compreender as diferenças, em um contexto de diversidade e complexidade e, ao mesmo tempo, promover a igualdade de tratamento para todos.

\section{ACESSO E PERMANÊNCIA DOS PCD'S NA EDUCAÇÃO SUPERIOR}

Referindo-se especificamente à educação superior, constata-se que a menção nos documentos legais é menos presente e mais recente. De forma genérica encontra-se inserido sempre que é sugerida a educação para todos e em todos os níveis, como, por exemplo, no art. 206, inciso I, da Constituição Federal (Brasil, 1988), "Igualdade de condições de acesso e permanência na escola”. Posteriormente, a Lei de Diretrizes e Bases (LDB), de 1996, apresenta um capítulo específico sobre educação superior; no entanto, foca-se na estrutura organizacional universitária e não nos aspectos da inclusão de pessoas com deficiência no ensino superior.

A partir dos anos 2000, a educação superior se torna mais presente nos textos legais, convergindo com um contexto que procura atentar para a diversidade e busca a evolução no processo de integração para inclusão. A exemplo disso, Convenção sobre os Direitos das Pessoas com Deficiência (CDPD), de 2006, busca assegurar um sistema de educação inclusiva em todos os níveis. Em 2007, o decreto 6.094 lança o Plano de Desenvolvimento da Educação (PDE), que propõe em seu texto o acesso e a permanência das pessoas com deficiência na educação superior. 
Atualmente, a Lei Brasileira de Inclusão (lei n. 13.146, de 6 de julho de 2015) propõe acesso à educação superior e à educação profissional e tecnológica em igualdade de oportunidades e condições com as demais pessoas. Recentemente, a lei 13.409/ 2016, modificou o texto original, de 2012, instituindo cotas no ensino superior federal para as pessoas com deficiência, além de negros, pardos e indígenas, bem como alunos de baixa renda oriundos da escola pública.

Tais políticas impactaram diretamente no acesso de Pessoas com Deficiência (PCD) aos cursos de educação superior. Segundo o Censo Escolar MEC/INEP (2006), houve um aumento de $107 \%$ nas matrículas, em relação à pesquisa anterior, em 1998, passando de 337.326 para 700.624 matrículas de pessoas com deficiência no ensino superior. No entanto, ainda não se tem $1 \%$ da população com deficiência cursando ensino superior; dados do MEC/INEP apontam para 0,42\%. Não se têm estatísticas oficiais sobre os índices de conclusão do ensino superior de pessoas com deficiência.

Os decretos sancionados ainda carecem de políticas para a implementação integral. Universidades e institutos públicos e federais contam com o programa Incluir (2005), do Ministério da Educação (MEC), que prevê verbas para adaptações arquitetônicas, capacitação de pessoas, aquisição de tecnologias para assegurar a acessibilidade plena das Pessoas com Deficiência.

Por outro lado, instituições privadas e comunitárias se deparam com o desafio de promover a acessibilidade; porém, não dispõem dos mesmos recursos, o que limita ainda mais a implantação de uma inclusão plena. 


\section{CONSIDERAÇõES FINAIS}

A partir deste breve recorte e da análise dos documentos legais, pode-se constatar que o País dispõe de vários dispositivos, decretos, resoluções e políticas, denotando um processo de preocupação em promover a integração das pessoas com deficiência na sociedade. No entanto, não se verifica a existência de estudos mais detalhados sobre a permanência desse público no ensino superior.

O processo de inclusão das pessoas com deficiência não se mostra linear como a evolução proposta pelos conceitos abordados nas seções anteriores. A garantia de matrículas não assegura por si só uma postura inclusiva por parte de educadores, colegas e sociedade em geral. É comum nos depararmos com comportamentos excludentes e discriminatórios, que remetem ao período da segregação.

De um modo geral, o que se tem vivenciado é a etapa de integração, visto que os decretos viabilizam o acesso, cobram a acessibilidade, que vem sendo implementada, basicamente, nos requisitos arquitetônicos e programas para efetivação das matrículas. Por outro lado, as barreiras atitudinais e de comunicação ainda persistem, levando o aluno com deficiência, muitas vezes, a estar sentado à classe do ensino superior, mas parecer invisível aos olhos dos que o cercam - seja por um entendimento equivocado de que a pessoa com deficiência deve ser tratada como as demais e buscar a sua própria adaptação, seja por "medo" do que é desconhecido.

Ainda é comum encontrar as "pessoas ditas normais", responsáveis pela implantação de projetos de acessibilidade e inclusão e, por suas "limitações", não compreenderem os diferentes modos de perceber e interagir das pessoas com deficiência, perpetuan- 
do a ideia da incapacidade dos diferentes. Agir com igualdade é promover condições equivalentes a todos, compreendendo a diversidade.

Relatos de uma acessibilidade plena, educação inclusiva, ainda são pontuais, mas devem ser valorizados e servir de exemplo para multiplicação e consolidação do direito ao ensino em todos os níveis e ao longo de toda a vida, para todas as pessoas, conforme preconiza a Lei Brasileira da Inclusão.

Apesar da consciência social ter avançado em relação aos direitos à inclusão, o desafio é por uma gestão educacional inclusiva que leve para uma cultura educacional inclusiva. Conclui-se que o tema continua relevante e que o Estatuto da Pessoa com Deficiência aponta para a necessidade de continuar avançando na busca por uma educação de qualidade e na adoção de boas práticas para alcançarmos uma inclusão plena e em prol de uma sociedade inclusiva, que viabilize condições adaptadas a todas as pessoas.

\section{REFERÊNCIAS}

ABRAMOWICZ, A. O debate sobre infância e a educação infantil na perspectiva da diferença e da multidão. In: Reunião Anual da Anped, 30, 2007. Anais... Eletrônico. Disponível em: <http://www.anped.org.br/>. Acesso em: 29 maio 2017.

BATISTA, C. A. M. Educação inclusiva: atendimento educacional especializado para a deficiência mental. Brasília: MEC, SEESP, 2006.

BRASIL. Lei de Diretrizes e Bases da Educação (1996): lei n. 9.394/96, de 20 de dezembro de 1996.

BRASIL. Constituição Federal. Brasília, 1988. 
BRASIL. Lei n. 13.409, de 28 de dezembro de 2016.

BRASIL. Marcos político-legais da educação especial na perspectiva da educação inclusiva, 2010.

BRASIL. Ministério da Educação. Secretaria de Educação Especial. Marcos político-legais da educação especial na perspectiva da educação inclusiva / Secretaria de Educação Especial. Brasília: Secretaria de Educação Especial, 2010.

BRASIL. PDE - Plano de Desenvolvimento da Educação: razões, princípios e programas, 2007.

CARVALHO, K. M. Os desafios da inclusão de pessoas com deficiência no ambiente de trabalho. In: CARVALHO-FREITAS, M. N.; MARQUES, A, L. (Org.) Trabalho e pessoas com deficiência. Curitiba: Juruá 2010.

DECLARAÇÃO DE SALAMANCA: sobre princípios, políticas e práticas em educação especial. Espanha, 1994.

LÜDKE, M.; ANDRÉ, M. E. D. A. Pesquisa em educação: abordagens qualitativas. São Paulo, EPU, 1986.

MARQUES, C. L. Educação profissional: o ingresso, as tecnologias e a permanência dos alunos com deficiência no Instituto Federal de Brasília. Universidade de Brasília, 2014.

MENEZES, E. T. de; SANTOS, T. H. dos. "Declaração de Salamanca" (verbete). Dicionário interativo da educação brasileira. EducaBrasil. São Paulo: Midiamix Editora, 2002.

SASSAKI, R. K. Inclusão: construindo uma sociedade para todos. 7. ed. Rio de Janeiro: WVA, 2006. 
SASSAKI, R. K. Vida independente: história, movimento, liderança, conceito, filosofia e fundamentos. São Paulo: RNR, 2003.

SILVA, T. T. da. Identidade e diferença: impertinências. Educação e sociedade. São Paulo, v. 23, n. 79 (ago. 2002). 